\title{
Research of Integration Micro-grid System based on DC Bus
} \author{
Changli Shi ${ }^{1, a}$, Xisheng Tang ${ }^{1, b}$, Yushu Sun ${ }^{1, c}$, Fufeng Miao ${ }^{1, d}$, Chao Gao ${ }^{1, \mathrm{e}}$ \\ ${ }^{1}$ Institute of Electrical Engineering Chinese Academy of Science, Beijing, 100190, China

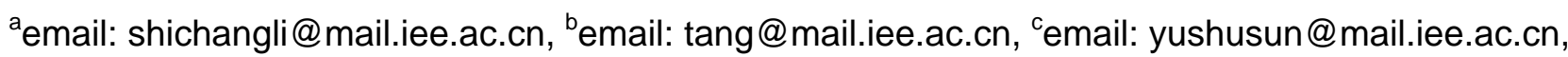 \\ demail: miaofufeng@mail.iee.ac.cn, ${ }^{e}$ email: gaochao@mail.iee.ac.cn
}

Keywords: Integration Micro-grid System based on DC Bus; Droop Characteristic; Optimal Energy Management Strategy

\begin{abstract}
In order to make use of Distributed Generation(DG) flexibly, the novel Integration Micro-grid System(IMGS) based on DC bus is proposed in this paper. The changing rule of photovoltaic array in a day is studied deeply. The control strategies based on droop characteristic are adopted by grid-connected module and energy storage module so that DC bus possesses droop characteristic similar to the traditional grid. On the basis of battery's working principle, a novel control strategy is proposed, and then Three-part Mode Charging (TMC) is achieved conveniently. In order to make IMGS working in optimum state all the time, the optimal energy management strategy is proposed. At last, a simulation platform is established in MATLAB/Simulink to verify the presented control methods.
\end{abstract}

\section{Introduction}

In order to solve energy crisis and environmental pollution, scholars around the world do a great deal of research and development work on renewable energy resources(RES),such as solar energy and wind energy. Micro-grid(MG) system is an advanced solution to utilize the RES effectively. Compared MG with AC bus system, the system with DC bus has more advantages, such as the elimination of phase and frequency synchronous problem, easier decoupling control, flexible configuration and so on. Recently, a lot of research has been done on DC bus system. An adaptive control system of DC MG for data centers is proposed [1], and the possible of the reliable power supply for sensitive load by the DC MG is studied. However, RES are not used in this system. A grid-connected photovoltaic system and its control strategy are proposed [2]. Once the battery bank is connected directly to the DC bus, the voltage of DC bus is difficult to keep stable. The stability of MG system with DC bus is explored [3,4], while the energy management of the system is not mentioned.

A novel Integration Micro-grid system (IMGS) based on DC bus is proposed in the paper. As shown in Fig.1, the photovoltaic array is connected to the DC bus through the PV module. The battery is linked to the DC bus through the energy storage module. The Grid is connected to DC Bus through the grid-connected module. The DC load is linked directly or through DC/DC converter to the DC bus. The AC load is linked to the DC bus through DC/AC converter. Since there is no load connected to Point of common coupling (PCC), the stand-alone operation mode of the system is omitted. Output characteristic of photovoltaic array in a day is studied deeply and output rules are made sure. Based on performance characteristics of battery, a novel control strategy of charging and discharging is proposed. The control strategy can achieve battery's TMC easily. Owing to droop characteristic, the voltage of DC bus can droop when battery discharges. The feed forward decoupling control based on droop characteristic is used in grid-connected module which could achieve energy exchanging between grid and DC bus. The voltage of DC bus which is proportional to the exchange energy is adjusted though droop characteristic. Based on characteristics of the functional modules, the typical energy flow states are proposed and the optimal energy management strategy is designs. Modularization and plug and play designed subsystems make the system easier of operation and maintenance. Finally, the effectiveness of the energy management strategy is verified by simulation in MATLAB/Simulink. 


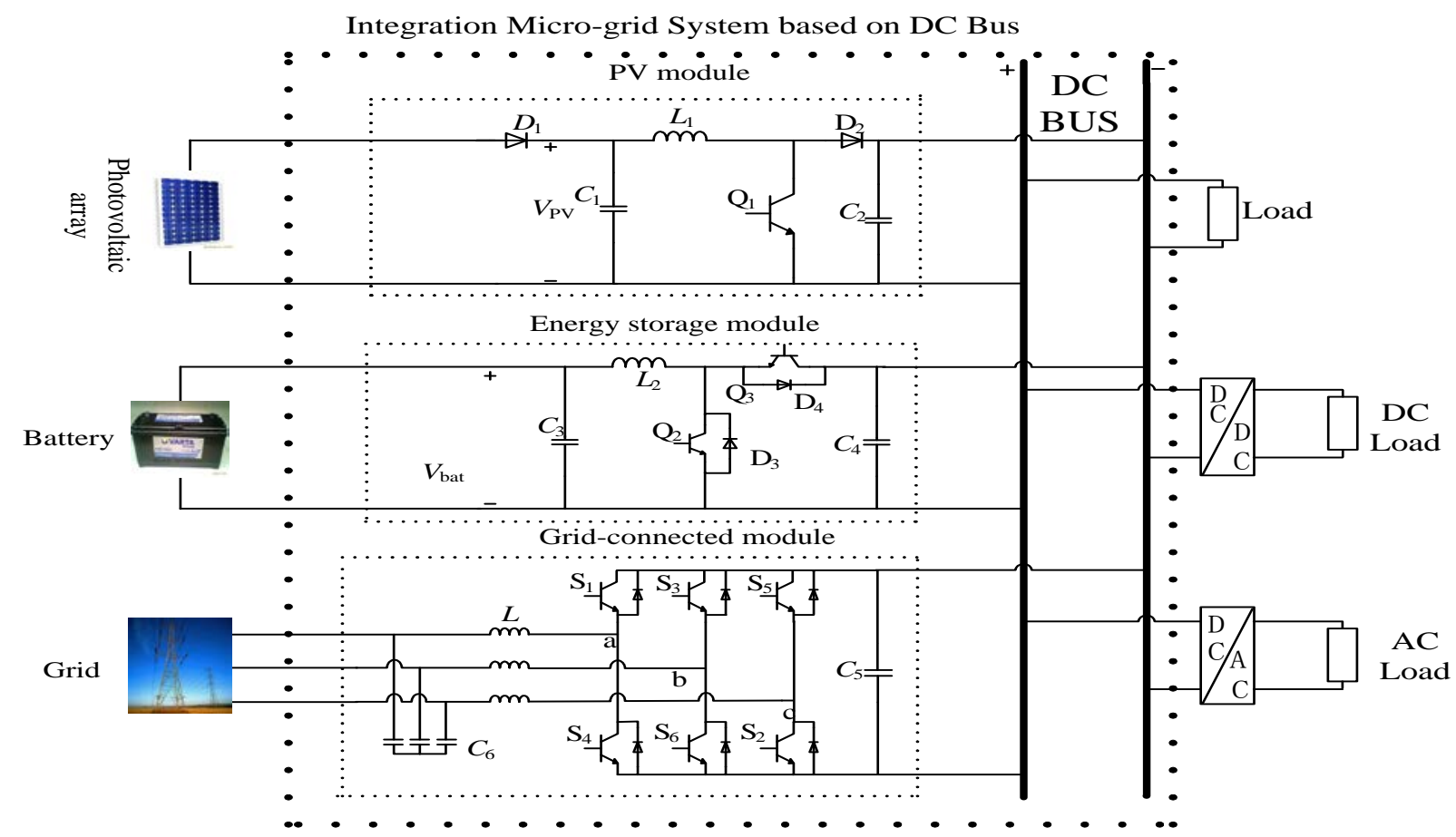

Fig.1. Main circuit of IMGS based on DC Bus

\section{Control Strategies of Functional Modules}

Photovoltaic array can provide with unique power flow direction towards the DC bus though PV module. In order to maximize the use of the power generated by the photovoltaic array, the Perturb\&Observe (P\&O) method is used to control PV operating at Maximum Power Point Tracking (MPPT). Normally, the photovoltaic array's working time is from dawn to dusk. In order to study a whole day output characteristic of photovoltaic array, some hypotheses are proposed.

(1) The variation range of illumination intensity is from $400 \mathrm{~W} / \mathrm{m}^{2}$ to $1000 \mathrm{~W} / \mathrm{m}^{2}$.

(2) The variation range of temperature is from $15^{\circ} \mathrm{C}$ to $30^{\circ} \mathrm{C}$.

(3) The simulation time is 12 seconds and one second stands for one hour.

As shown in Fig.2, the change curve of illumination intensity is:

$$
S=-\frac{50}{3} t^{2}+200 t+400
$$

The change curve of temperature is:

$$
W=-\frac{5}{12} t^{2}+5 t+15
$$

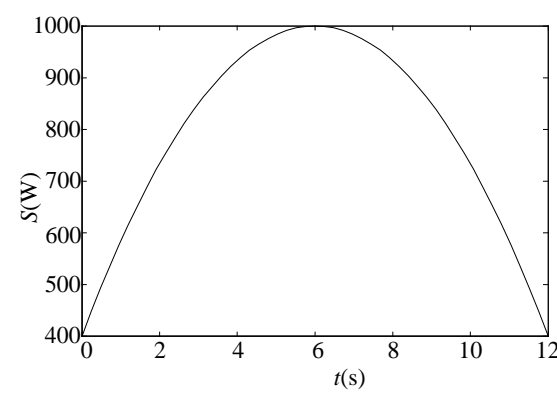

(a) The change curve of illumination intensity

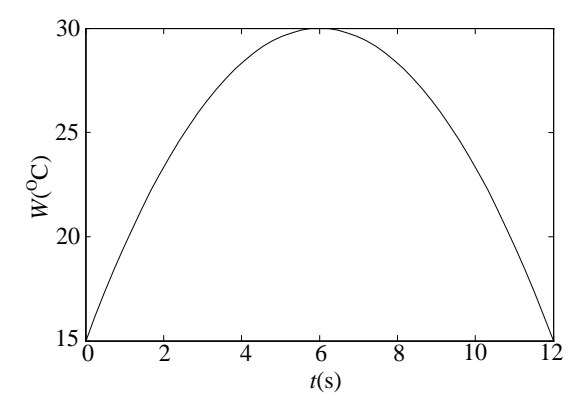

(b) The change curve of temperature

Fig.2. The curves of solar cells' external environment

The change curves of photovoltaic array's output characteristic are shown in Fig.3. With the changes of the illumination intensity and the temperature, the output current changes obviously while the output voltage has a slight fluctuation. Therefore, output voltage of photovoltaic array at maximum power point changes inconspicuously and the change of output power derives from the change of output current. 


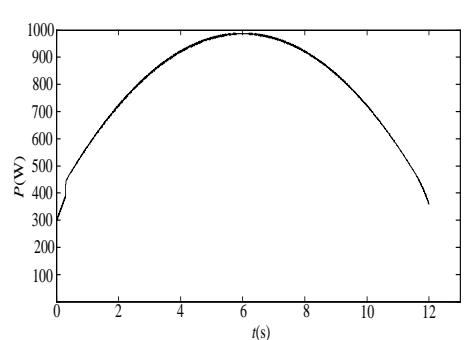

(a) The change curve of output power

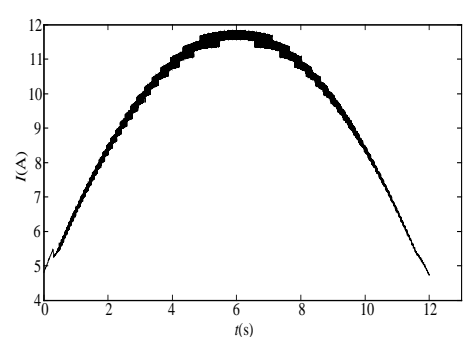

(b) The change curve of output current

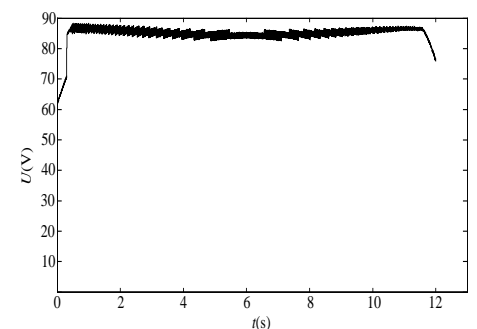

(c) The change curve of output voltage

Fig.3. The curves of solar cells' output characteristics

The control objective of energy storage module is to prolong working life under fulfilling application requirements. The control strategy of energy storage module is shown in Fig.4. Energy storage module adopts double closed-loop control strategy which includes the battery voltage outer loop and the inductance current inner current loop when battery needs charging. As a result of arranging the current limiter in the inner current loop, battery is charged by maximum current when the battery voltage is low. The inner current loop exits saturation when the battery voltage increases to a certain value, and then the voltage outer loop begins to play a role and battery is charged at constant voltage. When the battery voltage is close to the set value, the storage battery is charged by trickle current. The control strategy can be very convenient to achieve TCM charging and switch from charging modes smoothly. As shown in Eq.3 and Fig.5, the control strategy including the DC bus voltage outer loop and the inductance current inner loop based on droop characteristic when battery discharges. The DC bus voltage drops a certain value with battery discharge current increasing, and then the load energy demand decreases correspondingly. The discharging control strategy and the charging control strategy use the same current inner loop which reduces the complexity of the control strategy.

$$
U_{B U S}=U_{\text {BUSref }}-K * i_{L 2}
$$
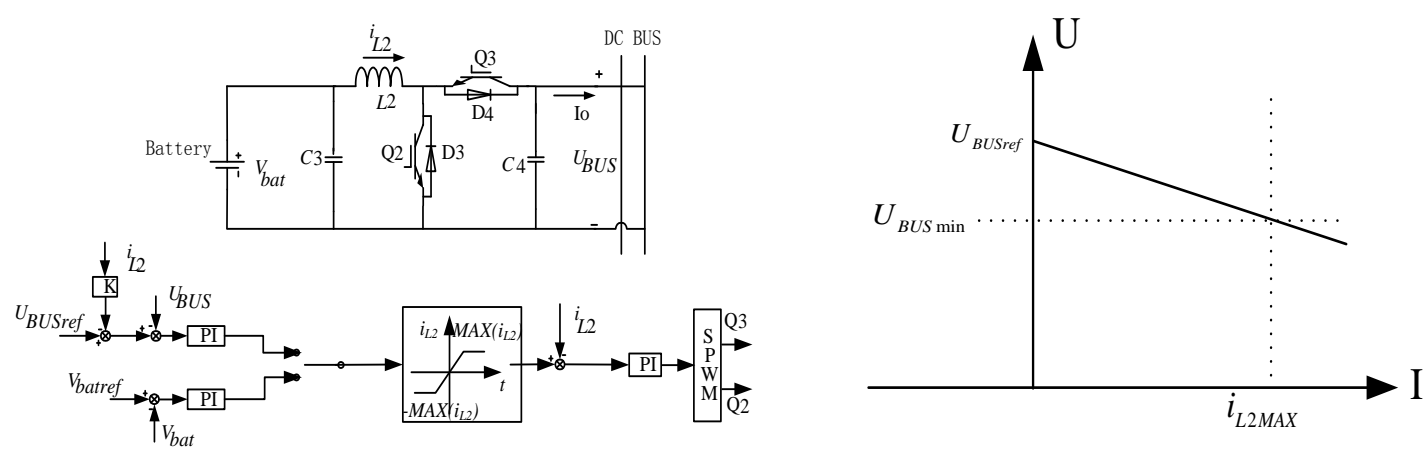

Fig.4. Control block diagram of energy storage module Fig.5. Droop control principle diagram

The control goals of grid-connected module is exchanging power between DC bus and grid and maintaining the DC bus voltage stability. The control strategy based on droop characteristic is shown in Fig.6 and Fig.7, which includes a feed forward decoupling control based on Eq.4 and Eq.5. If photovoltaic array provides energy greater than the need of load energy, the excess energy is injected into grid by the grid-connected module and the DC bus voltage rises in proportion. On the other hand, supplementary power can be supplied from the grid through the grid-connected module when the output power of the photovoltaic module is less than the load. The voltage of DC bus is lower when more power is obtained from the grid. Compared with AC MG system, the operation of the grid-connected module do not exist the problems such as the frequency control and phase synchronous, so the operation constraints is less and so the control is easier.

$$
\begin{aligned}
& \left\{\begin{array}{l}
v_{d}=-G_{d f}(s)\left(i_{d}^{*}-i_{d}\right)+w L i_{d}+e_{d} \\
v_{q}=-G_{d f}(s)\left(i_{q}^{*}-i_{q}\right)-w L i_{q}+e_{q}
\end{array}\right. \\
& \boldsymbol{U}_{B U S}=\boldsymbol{U}_{\text {BUSref }}-K_{1} * \boldsymbol{i}_{G}
\end{aligned}
$$




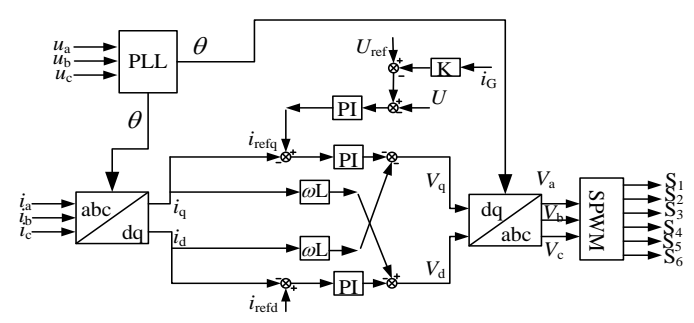

Fig.6. The control block diagram of grid-connected module based on droop control

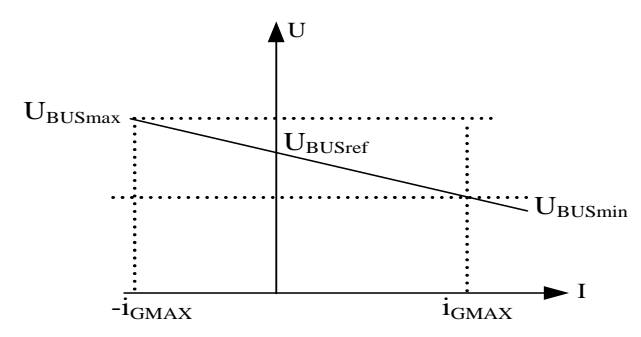

Fig.7. The droop characteristic diagram of grid-connected module

\section{The Optimal Energy Management Strategy of IMGS}

The optimal energy management strategy should be able to make full use of the photovoltaic energy, to keep the voltage of the DC bus within the permissible range, and to reduce battery charging/discharging cycle to extend its lifetime. Five typical energy flow states exist in the studied system, as shown in Fig.8.

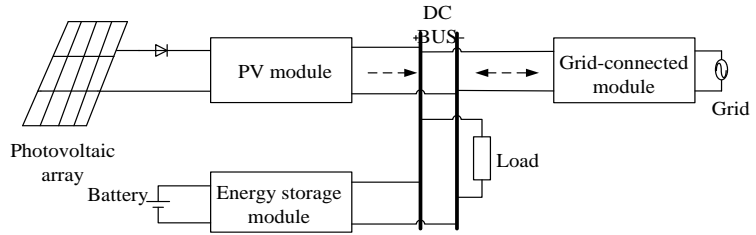

(a) Energy flow state(1)

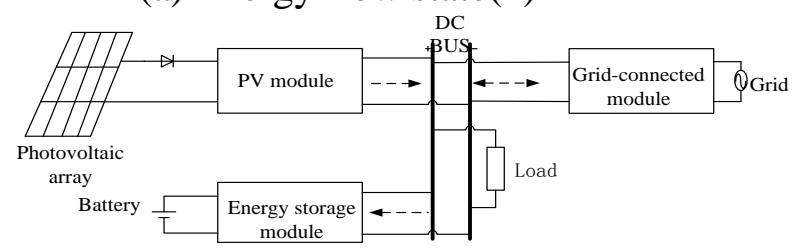

(c) Energy flow state(3)

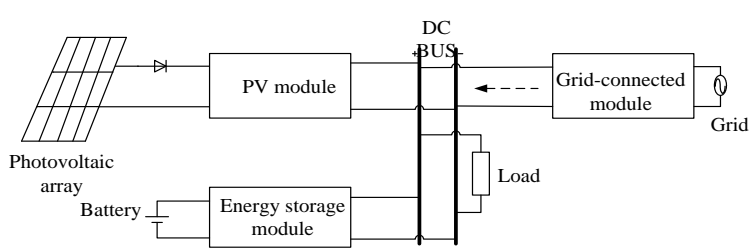

(b) Energy flow state(2)

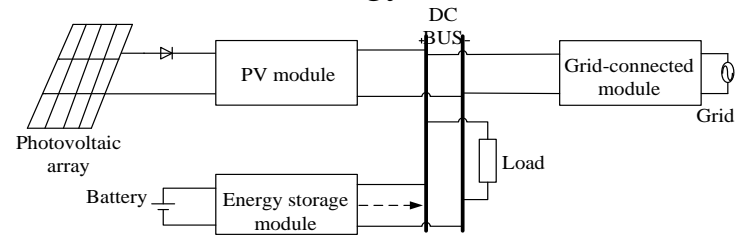

(d) Energy flow state(4)

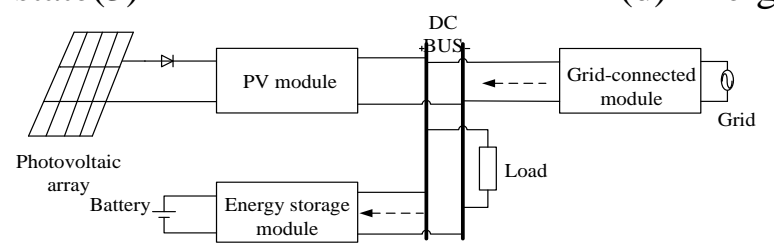

(e) Energy flow state(5)

Fig.8. Energy flow states of system

The Fig.8(a) is corresponding to energy flow state(1). Here the PV module generates power and the battery is fully charged. The PV module works in MPPT mode, the energy storage module stops working, and the grid-connected module works according to the condition of the PV module and the load. If the power of the PV module is more than the load, the grid-connected module works in inverter mode, otherwise it works in rectifier mode. The grid-connected module is responsible for the stability of the DC bus voltage. The energy flow state(2) shown in Fig.8(b) represents the situation when the PV module can't provide power at night, in cloudy or rainy days. The battery's state of charge is $100 \%$, and the load is supplied by the AC gird only. The PV module and energy storage module stop working, the grid- connected module working in rectifier mode. In Fig.8(c), the PV module gives energy and the battery is charged until it is full. The PV module works in MPPT mode, and the grid-connected module works mode is ascertained according to the power needed considering both the load and the charging power of the battery. When faults happen in the grid, the PV module and the grid-connected module stop working, and the energy storage module works in discharging mode to keep the voltage of DC bus stable and supply the load. This kind of conditions is shown in Fig.8(d). In Fig.8(e), for the cloudy, rainy weather or at night, the PV module doesn't give out electric energy meanwhile the battery isn't fully charged. The grid-connected module is used as a rectifier to keep the voltage of the DC bus stable and further to supply the load and charge 
the battery. The energy storage module is in charging operation mode.

By the way, in order to make the analysis easier, the hypothesis is done.

$$
N=\left\{\begin{array}{l}
1 \\
0
\end{array}\right.
$$

1 is stand for grid getting out of order and 0 represents grid in normal state.

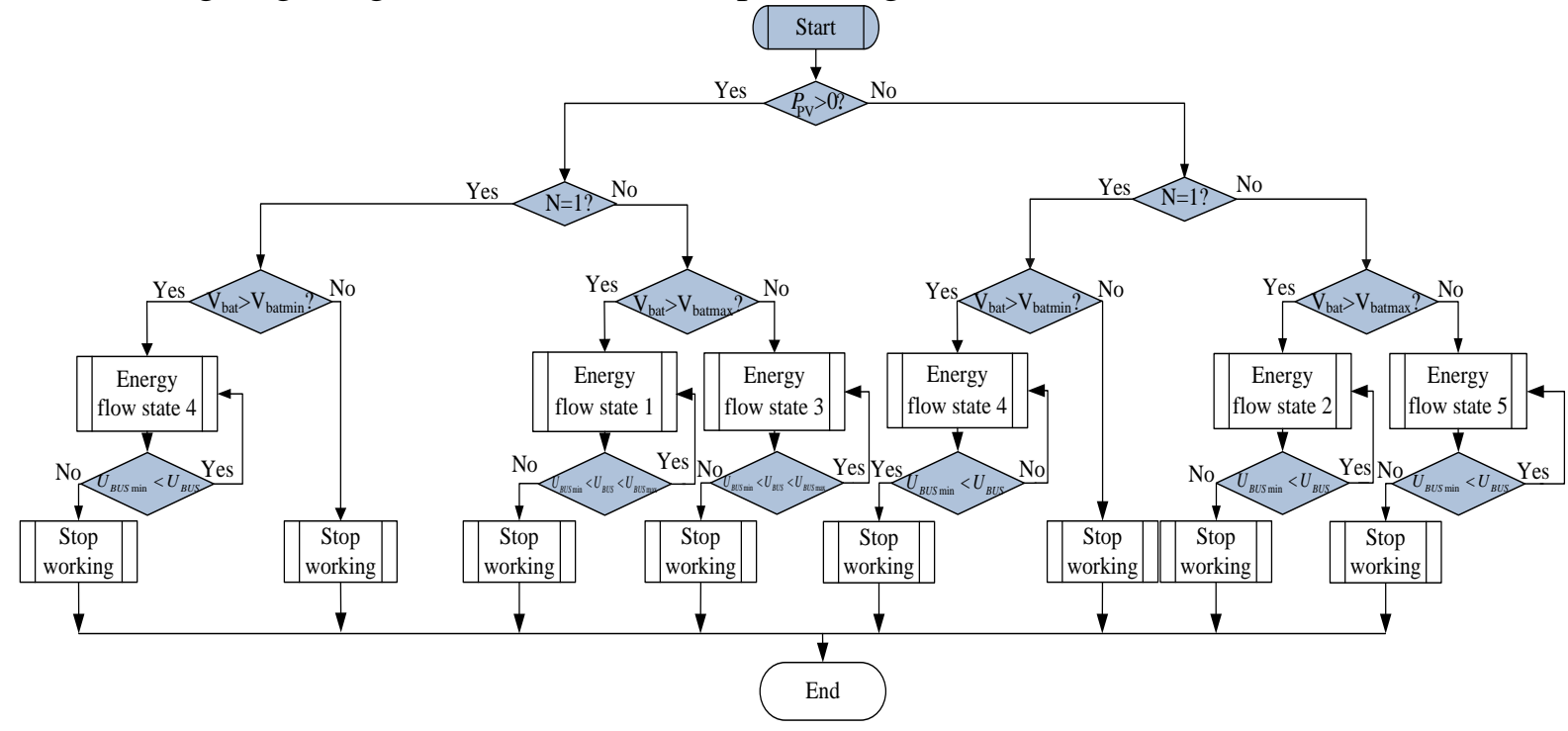

Fig.9. The control flow chart of the system

The judgment of energy flow state and the transition between different states are shown in Fig.9. Because the photovoltaic array can give out energy and the voltage of battery is higher than $V_{\text {batmin }}$ with the grid isn't normal, the IMGS working in energy flow state(4). If the voltage of DC bus is higher than the $V_{\text {busmin }}$, the system works normally, otherwise it stops working. On the other hand, the system stops working when the battery's voltage is lower than the $V_{\text {bat } \min }$. When photovoltaic array can provide power and the grid has no faults, the system working in energy flow state(1) if battery's voltage is higher than $V_{\text {bat max }}$. At this time, if the voltage of DC bus is at the reasonable interval, the system works normally, otherwise it stops working. Another kind of circumstance, because the $V_{\text {batmax }}$ is higher than the voltage of battery, the IMGS stays at energy flow state(3).The system works in order when DC bus voltage is in the reasonable range, otherwise it shuts down. When the photovoltaic array can't generate power and the grid has malfunction, the system's operation mode is energy flow state(4). The IMGS stops working if DC bus voltage lower than $V_{\text {busmin }}$, or else it is in normal operation. If photovoltaic array can't provide electric energy and grid is in normal condition meanwhile the voltage of battery is higher than $V_{\text {bat max }}$, the IMGS gets into energy flow state(2). DC bus's voltage overtop $V_{\text {busmin }}$ occurs, the system works normally, if not it does not work. The system's operation mode is energy flow state(5) when battery need recharging. If the voltage of DC bus is lower than $V_{\text {busmin }}$, the system stop working, otherwise it works in normal mode.

\section{Simulation Results and Discussion}

To verify the effectiveness of the system structure and corresponding control strategies, a simulation system is set up in MATLAB/Simulink. As shown in Fig.10, the battery is fully charged, Illumination intensity changes from $1000 \mathrm{~W} / \mathrm{m}^{2}$ to $800 \mathrm{~W} / \mathrm{m}^{2}$ at $\mathrm{t}=0.4 \mathrm{~s}$, and then $0 \mathrm{~W} / \mathrm{m}^{2}$ at $\mathrm{t}=0.8 \mathrm{~s}$. The output power of photovoltaic array changes from $2900 \mathrm{~W}$ to $2300 \mathrm{~W}$ at $\mathrm{t}=0.4 \mathrm{~s}$, and then $0 \mathrm{~W}$ at $\mathrm{t}=0.8 \mathrm{~s}$. As shown in Fig.11, the output power of the photovoltaic array is more than the load before $0.4 \mathrm{~s}$ and the redundant energy can be fed into the grid by grid-connected module. Between $0.4 \mathrm{~s}$ and $0.8 s$, the output power of photovoltaic array is less than the load and then supplementary power can be supplied from the grid by grid-connected module. The photovoltaic array can't generating power after $0.8 \mathrm{~s}$, and the load is supplied by the grid only. The change trend of DC bus 
voltage is shown in Fig.12. As a result of the influence of droop characteristic, the voltage of DC bus is slightly higher than $200 \mathrm{~V}$ before $0.4 \mathrm{~s}$ and slightly lower than $200 \mathrm{~V}$ between $0.4 \mathrm{~s}$ and $0.8 \mathrm{~s}$, and then the DC bus's voltage further down after $0.8 \mathrm{~s}$. The voltage of DC bus is within $\pm 25 \mathrm{~V}$ in the whole process, which meets the requirement. The system transits from energy flow state (1) to state (2). The conversion process between other energy flow states is the same. It can be seen that due to the modularization designed structure and the energy management strategies, the IMGS can transit from energy flow states without affecting system normal operation.

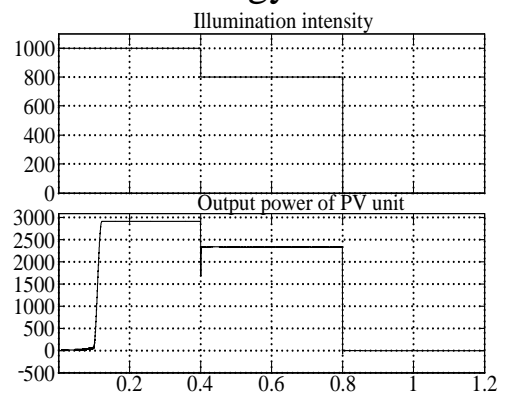

Fig.10. Output waves of PV module

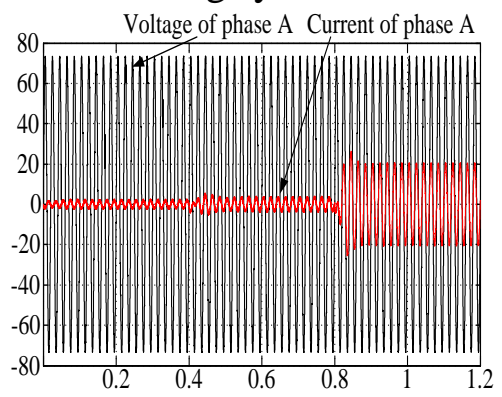

Fig.11. The waves of grid-connected interface module

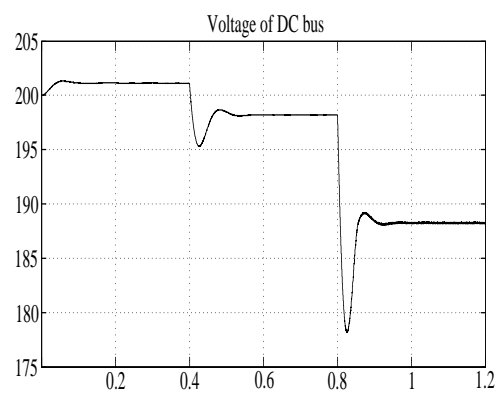

Fig.12. The wave of DC bus's voltage

\section{Conclusion}

A novel integration micro-grid system based on DC bus is presented in this paper, which integrates a MG system into a single device. Modularization and plug and play design make the operation and maintenance of the IMGS easily. The control strategies of functional modules are designed, and the optimal energy management strategies based on energy flow states is proposed. The proposed system structure and energy management strategies are verified in a simulation platform established in MATLAB/Simulink. The system structure and the corresponding energy management strategies proposed can make the IMGS based on DC bus work in the optimal state.

\section{Acknowledgement}

In this paper, the research was sponsored by the Development Major Program of China (No.2014AA052002), the Key Project of the CAS Knowledge Innovation Program (KGCX2-EW-330), and the technology project of State Grid (SGSHJY00BGJS1400221).

\section{References}

[1] D. Salomonsson, L. Söder and A. Sannino: Industry Application, IEEE Transactions,Vol. 44 (2007), p.2414

[2] Y. Gurkaynak, A. Khaligh: Applied power Electronics Conference and Exposition(APEC), Twenty-Fourth Annual IEEE . (2009),p.2086

[3] T.-F Wu, L.-C Lin: Applied power Electronics Conference and Exposition(APEC), Twenty-Seventh Annual IEEE.(2012),p. 377

[4] T-F Wu, C-L Kuo: Energy Conversion Congress and Exposition (ECCE). (2011), P.4161

[5] H. Liang: Study on Maximum Power Tracking and Batteries Examination in Stand-alone Photovoltaic System ( M.E., Yanshan University, China 2008),p.28.

[6] H. Kakigano, Y. Miura and T. Ise : Transmission \& Distribution conference \& Exposition. (2009),p.1-4

[7] H. Kakigano, Y. Miura and T. Ise : Power Electronics, IEEE Transactions.Vol.25(2010), p.3066 